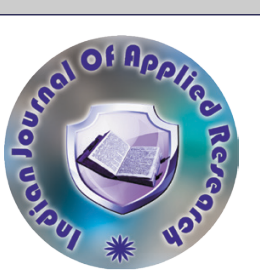

Gynaecology

\title{
DOPPLER STUDY IN PREDICTING IUGR AND PRENATAL OUTCOME IN PIH
}

\author{
Dr.k. Thamara \\ Veni* \\ Dr.Gadam Swathi Ms (Obg) \\ Ms (Obg), Dgo *Corresponding Author
}

\section{KEYWORDS :}

\section{INTRODUCTION}

Normal fetal growth and development depends on adequate perfusion of the intervillous space through the maternal spiral arterioles. Reduced perfusion is associated with asymmetrical retardation of the fetal growth and fetal hypoxia that is the major cause of perinatal mortality.

Pregnancy induced hypertension (PIH) remains the major cause of maternal and perinatal morbidity and mortality. With the help of colour Doppler, the identification of vessels that are evaluated for Doppler study can become simple ${ }^{1}$. Hence role of Doppler examination has become indispensable in screening, diagnosis and management of PIH and IUGR cases. ${ }^{2}$. With the aid of colour Doppler, IUGR can be diagnosed before it is clinically evident.

In the present study, we examined flow velocity waveforms in uteroplacental (uterine artery and umbilical artery) and fetoplacental (middle cerebral artery) circulations in both normal pregnancy ${ }^{3}$ and in situations of suspected placental insufficiently such as PIH and IUGR pregnancies ${ }^{4}$. Subsequently result in birth of growth retarded infant, to derive pathophysiological information about placental flow resistance and assess the diagnostic potential of this measurement.

\section{AIMS AND OBJECTIVES}

An important goal in contemporary obstetrics is to identify growth retarded fetus at risk for perinatal morbidity and mortality. Doppler provides noninvasive method of assessing fetal and maternal circulations in pregnancy and it can identify IUGR and adverse perinatal outcome associated with abnormal utero placental circulation

Our study was an effort at establishing the role of UA and MCA Doppler ultrasound in predicting adverse perinatal outcomes in clinically diagnosed pregnancy induced hypertension cases and to determine the role of Doppler velocimetry in clinical management of such pregnancies.

\section{Aims and Objectives:}

1. To evaluate the blood flow velocity pattern in uteroplacental and fetoplacental circulations using Doppler ultrasound in pregnancy induced Hypertension (PIH) in our population.

2. To detect adverse perinatal outcome by Doppler in PIH cases.

3. To analyze the significance of different Doppler parameters taken in predicting IUGR and perinatal outcome in PIH.

4. To compare the results of our study with similar studies available in the present literature.

\section{MATERIALS AND METHODS}

The present study comprises of 80 antenatal cases from the Dept. of Obstetrics and Gynaecology, Viswabarathi Medical college \& Hospital, Kurnool District for Doppler evaluation of clinically diagnosed pregnancy induced hypertension for perinatal outcome and IUGR.

These cases were evaluated in the Dept. of Radiodiagnosis with ESOATE MEGAS GPX machine evenly 3.5 MHz convex array transduces. The period of study was 12 months from February 2019 to January 2020 .

In the present study, an attempt is made to assess the utility of various flow velocities waveform as screening tool for diagnosis of IUGR and abnormal perinatal outcome taken into consideration are systolic / diastolic ratio, pulsatality index and resistance index of umbilical artery and middle cerebral artery.

Eighty cases of hypertension complicating pregnancy comprised the present study.

The first scan was performed in each case as soon as the patient was admitted to the ward in order to avoid any influence of treatment on Doppler sonogram routine U/S screening was performed in each case followed by Doppler waveform analysis of fetal umbilical artery and MCA. The scan was repeated in intervals depending on severity of hypertension and abnormalities of waveform. The cases were followed till the time of delivery during the puperperium and perinatal outcome was noted.

\section{Doppler Criteria:}

Umbilical artery $>2 \mathrm{SD}$ and $\mathrm{MCA}<5 \%$ percentile is taken as abnormal.

Outcome criteria :

Major - Intra uterine/early neonatal death, HIE, IVH, PVL Parenchymal Haemorrhage.

Minor - Apgar $<7$ at $5 \mathrm{~min}$. admission to NICU

\section{Examination method}

Doppler examination was done when the fetus was in apnoecstate to avoid the influence of fetal respiration on Doppler study of umbilical artery.

\section{Identification of Umbilical Artery :}

Umbilical artery measurements were done both in a freefloating loop that is close to the fetus and in a second site which is about $2 \mathrm{~cm}$ away from placental insertion.

$$
\begin{array}{ll}
1-2 \mathrm{~cm} & - \text { diameter } \\
2 & - \text { arteries } \\
1 & \text { - vein }
\end{array}
$$

Spiraling of card with 0-4 twists

Site of Doppler - Close to the placenta is performed

$\mathrm{S} / \mathrm{D}$ increases with - Sample site closer to fetus. Increases H.R.

Decrease with lateral decumbitus position.

\section{Identification of MCA :}

The MCA can be visualized in a transverse axial view of fetal head at a slightly more caudal plane than one used for biparietal diameter measurements. At this level that includes the cerebral pedumcles the MCA can be seen as major lateral branch of circle of Willis coursing anterolaterally towards the lateral edge of orbits at the level of lesser using of the sphenoid bone into lateral sulcus and disappearing on to cerebral fossa between the insula and the temporal lobe. The sample volume should be placed at the proximal part of MCA.

\section{OBSERVATIONS AND RESULTS}

Table-1 Total no. of cases 80

\begin{tabular}{|l|l|l|}
\hline Study Group & Number & Percentage (\%) \\
\hline No. of cases abnormal Doppler & $32 / 80$ & 40 \\
\hline Normal Doppler & $48 / 80$ & 60 \\
\hline
\end{tabular}


Volume - 10 | Issue - 9 | September - 2020 | PRINT ISSN No. 2249 - 555X | DOI : 10.36106/ijar

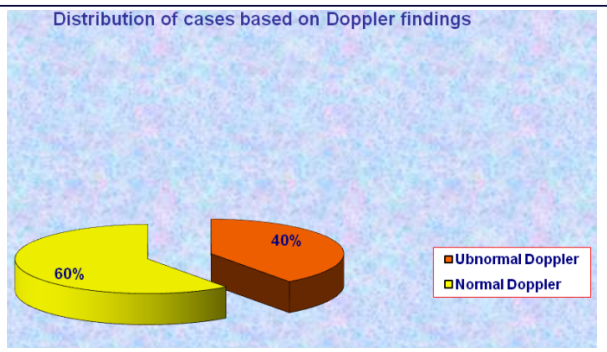

Table-2

\begin{tabular}{|c|c|c|}
\hline Abnormal Doppler & Normal Outcome & Adverse perinatal outcome \\
\hline 32 & 12 & 20 \\
\hline
\end{tabular}

Table-3 Umb. Artery Study

Significance of absent or Reverse end diastolic flow.

\begin{tabular}{|c|c|c|c|}
\hline & Kurkinen Ratty (1991) & Karsador P & Present study \\
\hline AEDV & $8.1 \%$ & $41 \%$ & $75 \%$ \\
\hline REDV & $35.7 \%$ & $75 \%$ & $100 \%$ \\
\hline
\end{tabular}

In our study we found that absent or reverse of end diastolic velocity in umbilical artery is more sensitive in predicting adverse fetal outcome comparable with study done by Kurkinen Ratty (1977) and Karsador (1994).

Table-4 PI of MCA and Umb.A:

\begin{tabular}{|c|c|c|c|}
\hline Parameter & Rhee \& Detti & Katherine W.Fong & Present study \\
\hline PI of Umb.A. & $63 \%$ & $58.3 \%$ & $75 \%$ \\
\hline PI of MCA & $85 \%$ & $91.7 \%$ & $75 \%$ \\
\hline
\end{tabular}

According to Katherine W. Fong the PI value of MCA is more sensitive. According to Meenakshi PI value is equivocal, in our study, PI value of Umb.A and MCA are equivocal.

\section{Table-5}

\begin{tabular}{|l|l|l|l|l|}
\hline & Parameter & $\begin{array}{l}\text { Catherine } \\
\text { W.Fong }\end{array}$ & $\begin{array}{l}\text { Dandoho } \\
\text { Gamellini }\end{array}$ & $\begin{array}{l}\text { Present } \\
\text { study }\end{array}$ \\
\hline Umb.A. & Sensitivity & $58.5 \%$ & $64 \%$ & $75 \%$ \\
\hline & Specificity & $81.8 \%$ & $90.7 \%$ & $98.3 \%$ \\
\hline & PPV & $22.2 \%$ & $72.7 \%$ & $93.3 \%$ \\
\hline & NPV & $95.7 \%$ & $86.7 \%$ & $92.2 \%$ \\
\hline MCA & Sensitivity & $91.7 \%$ & $24 \%$ & $75 \%$ \\
\hline & Specificity & $53.9 \%$ & $100 \%$ & $75.4 \%$ \\
\hline & PPV & $15.1 \%$ & $100 \%$ & $50 \%$ \\
\hline & NPV & $98.6 \%$ & $77.3 \%$ & $92 \%$ \\
\hline
\end{tabular}

\section{Table-6}

\begin{tabular}{|l|l|l|l|}
\hline MCA/UA PI & Gramellini et all & Fong K.W. et al & Present Study \\
\hline Sensitivity & $68 \%$ & $51.3 \%$ & $82 \%$ \\
\hline Specificity & $98.4 \%$ & $80.6 \%$ & $91 \%$ \\
\hline PPV & $94.4 \%$ & $48.1 \%$ & $78 \%$ \\
\hline NPV & $88.8 \%$ & $82.5 \%$ & $73 \%$ \\
\hline
\end{tabular}

MC Parlond-Among the UA-PI is highest specificity, Sensitivity NPV and PPV Absent/reversal diastolic flow with in UA is the grave prognosis. In our study UA PI is highest specific and PPV than RI and $\mathrm{S} / \mathrm{D}$ ratio

\section{Table-7}

Comparison of our study with study done by B.N. Lakhkar, K.V.

Rajgopal, PT Gowri Sankar (2005)

\begin{tabular}{|l|l|l|}
\hline Parameter & K.V.Raj Gopal & Present study \\
\hline Umb. RI & & \\
\hline Sensitivity & $58 \%$ & $95.2 \%$ \\
\hline Specificity & $56.5 \%$ & $76.6 \%$ \\
\hline PPV & $35 \%$ & $62 \%$ \\
\hline NPV & $86.8 \%$ & $97.2 \%$ \\
\hline PI & & \\
\hline Sensitivity & $58 \%$ & $75 \%$ \\
\hline Specificity & $56 \%$ & $98.3 \%$ \\
\hline PPV & $35 \%$ & $93.3 \%$ \\
\hline NPV & $86.8 \%$ & $92.2 \%$ \\
\hline S/D & & \\
\hline Sensitivity & $75 \%$ & $86.9 \%$ \\
\hline Specificity & $41.3 \%$ & $77.2 \%$ \\
\hline \hline
\end{tabular}

\begin{tabular}{|l|l|l|}
\hline PPV & $25 \%$ & $60.6 \%$ \\
\hline NPV & $86.3 \%$ & $93.6 \%$ \\
\hline MCA & & \\
\hline Sensitivity & $61.6 \%$ & $75 \%$ \\
\hline Specificity & $71.7 \%$ & $75.4 \%$ \\
\hline PPV & $47 \%$ & $50 \%$ \\
\hline NPV & $93.7 \%$ & $92 \%$ \\
\hline $\begin{array}{l}\text { MCA/UA } \\
\text { S/D Ratio }\end{array}$ & & \\
\hline Sensitivity & $83 \%$ & $90 \%$ \\
\hline Specificity & $75 \%$ & $95 \%$ \\
\hline PPV & $38.4 \%$ & $85.7 \%$ \\
\hline NPV & $93.7 \%$ & $96.6 \%$ \\
\hline $\begin{array}{l}\text { MCA/UA } \\
\text { PI }\end{array}$ & & \\
\hline Sensitivity & $66.6 \%$ & $82 \%$ \\
\hline Specificity & $73.9 \%$ & $91 \%$ \\
\hline PPV & $40 \%$ & $78 \%$ \\
\hline NPV & $89.4 \%$ & $73 \%$ \\
\hline
\end{tabular}

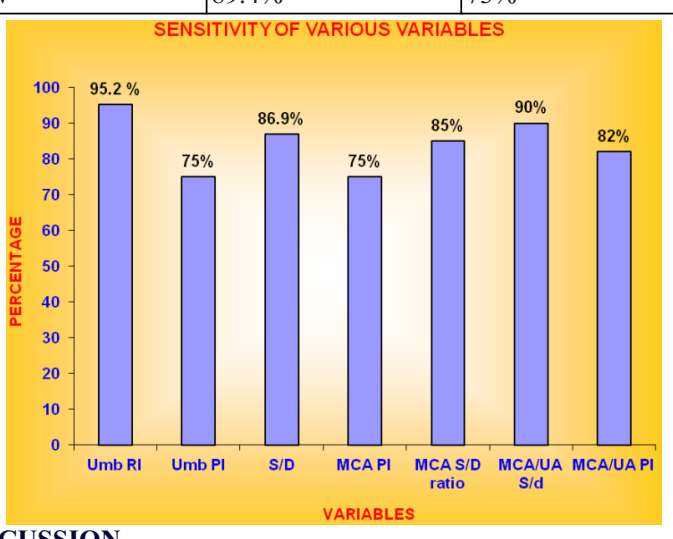

DISCUSSION

In our study, we have taken eighty clinically suspected PIH/IUGR cases along with equal number of controls.

The highest number of cases in our study is between 21-30 years followed by below 20 years of age.

In the literature, the criteria for cerebral redistribution of vary, including MCA pulsatality index below the $5^{\text {th }}$ percentile, MCA PI below $2 \mathrm{SD}$, UA/MCA. Pulsatality index ratio greater than $0.72 \%$, UA/MCA pulsatality index ratio above the $95^{\text {th }}$ percentile, UA/MCA $\mathrm{RI}>1.0 \mathrm{MCA} / \mathrm{UA}$ RI below 1.0 and MCA/UA PI ration of less than 1.08 comparision between different studying would be more meaningful of uniform (or) standardized criteria were used.

In the study group thirty three $62.5 \%$ cases show abnormal Doppler findings consistent with adverse perinatal outcome and the remaining seventeen $37.5 \%$ does not show any evidence of adverse outcome on any single parameter.

\section{Umbilical Artery:}

Systolic to diastolic ratio (S/D ratio) - More than 3 after 30 weeks is abnormal (Adiel Fleishcher 1985). In our study, the maximum number of cases $20 / 80(25 \%)$ show abnormal S/D ratio. Of these $60.6 \%$ cases show adverse outcome.

\section{Pulasatality Index (PI):}

It is increased in cases of PIH and IUGR. In our study the PI value is increased in 15/80 (18.7\%) of cases of these 93\% shows adverse outcome as comparable with study done by John Vugt.

\section{Resistance Index :-(RI)}

The normal value of RI is the umbilical artery is 0.6 . It is elevated in cases of PIH and IUGR. In our study, 32/80 (38.7\%) of cases that show abnormal resistance index. Of these $62.5 \%$ shows adverse outcome.

In our study, sensitivity of $\mathrm{S} / \mathrm{D}$ ratio $\mathrm{Pi}, \mathrm{RI}$ is $86.9 \%, 75 \%, 95 \%$ respectively and PPV $-60.6 \%, 95.5 \%, 62.5 \%$. In our study we found abnormal PI ratio is more sensitive among other parameters, comparable with study done by Harington K (1995), Bhushan N Lakhar(1999). 


\section{Absent or Reversal of End diastolic velocity:-}

In our study, we found $17.5 \%$ reversal/absent of EDV. Absent diastolic flow seen in 10 cases. Of these 7 cases admitted in NICU with severe respiratory distress.

Kurkinen - Ratty M et al (1997)- In their study of 83 fetuses with absent / reversal EDV, perinatal mortality rate was 19\%. The perinatal mortality rate in AEDV $8.1 \%$ is REDV in $35.7 \%$

VHM Karsdorp et al (1994). In their study of high risk pregnancies (PIH, IUGR), the over al perinatal mortality rate was $28 \%$, perinatal deaths was $41 \%$ in absent end diastolic, $75 \%$ in reversal end diastolic velocity.

Our study shows absent or reversal of EDV of more sensitive in predicting adverse fetal outcome comparable with study done by Katherine D Wenstrom (1991) Karsador (1994) and Kurkinen Ratty (1997).

\section{FETALMIDDLE CEREBRALARTERY (MCA):}

The normal PI value of MCA in 28 weeks of gestation is 1.60 .4 and at 40 weeks. 1.2 0.4. Only one third of cases show abnormal MCA Doppler finding in the present study. According to Katherine W. Fong, the criteria for cerebral redistribution are as follows:

a) Ratio of PI of umbilical artery / MCA more than 0.72 .

b) Ratio of RI of umbilical artery / MCA more than 1 .

c) Ratio of RI of MCA/ Umbilical artery less than 1.

In our study $\mathrm{PI}$ of MCA/UA ratio is more sensitivity, specificity and PPV comparable to that of Gramellini et al. according to Katherine W. Fong PI of MCA is more sensitivity. In our study UA PI more specificity and PPV than MCAPI.

\section{SUMMARY}

1. A Doppler index that reflects both of these areas can be useful for identifying fetuses with increased placental and/or decreased cerebral resistance.

2. PI varies in relation to the intracranial artery considered, so it is important that the artery be identified precisely and with certainty.

3. In the evaluation of the fetal cerebral circulation, the MCA is the most accessible vessel and it can be easily located on colour Doppler therefore the vessel of choice. It is the main branch of the circle of Willis and carries $80 \%$ of the blood flow to the ipsilateral cerebral hemisphere, a constant $3 \%-7 \%$ of cardiac output throughout gestation. Hence, we used middle cerebral artery for the evaluation of fetal cerebral circulation.

4. We studied the Doppler index of umbilical artery only after $30^{\text {th }}$ week, because in agreement with Schulman, Gramellini we believe that it is difficult of define normal or abnormal umbilical flow velocity before $30^{\text {th }}$ week, with the exception of absent end diastolic flow velocity after $20^{\text {th }}$ week. Furthermore in most cases clinical issues concerning asymmetrical growth retardation (placental insufficiency) arise after the $30^{\text {th }}$ week.

5. It is possible to use a single cut off value for cerebroplaental ratio after $30^{\text {th }}$ week because cerebral-umbillical Doppler ratio does not vary significantly between $30^{\text {th }}$ and $40^{\text {th }}$ weeks as reported by Wladimiroff et $\mathrm{al}^{6}$ who observed a significant differences in cerebroplacental ration only between weeks 26-38.

6. Arbeille et al also found the cerebral-placental ration constant during the pregnancy and suggested 1 as the cut off value; all values below 1 were considered abnormal.

7. In the literature, the criteria for cerebral redistribution vary, including an MCA pulsatililty index below the $5^{\text {th }}$ percentile, MCA pulsatility index below $2 \mathrm{SD}(26)$, UA/MCA pulsatality index ratio greater than 0.72 , UA/MCA pulsatility index ratio above the $95^{\text {th }}$ percentile, UA/MCA resistance index ratio above 1.0 , $\mathrm{MCA} / \mathrm{UA}$ resistance index ratio below 1.0 and MCA/UA PI Ratio of less than 1.08 .

8. According to Arduini, Rizzo et al and Gramillini D, FolliMC, et alcerebral ambillical ratio at best index for predicting adverse perinatal outcome compare with MCA/and Umb.A alone.

In our study cerebro-placental ratio (PI) shows high sensitivity than UA and MCA done comparable with previous study. In our study, UA PI has highest PPV and specificity than other studies.

Umb RI, PI, S/D and MCA PI level significant NPV among umb. PI shows highest NPV than others.

\section{CONCLUSION}

Antenatal Doppler study is noninvasive method predicting the adverse perinatal outcome and IUGR in pregnancy induced hypertension. If detects cerebro placental compromise, hypoxia earlier than biophysical profile, NST and cardiotopography.

In our study $\mathrm{MCA} / \mathrm{S} / \mathrm{D}, \mathrm{MCA} / \mathrm{UA} \mathrm{S} / \mathrm{D}$ ratio $(90 \%, 86.9 \%)$ shows highest sensitivity than other parameters. (MCA/UAPI, UAPI)

In our study umbilical and middle cerebral artery flow indices significantly affecting the adverse perinatal outcome and foetal hypoxia in pregnancy induced hypertension to as compared to other studies.

In our study, Umb Artery PI is more PPV than other parameters and Umb. Artery RI is more NPV than other parameters.

Finally, we recommend the Doppler studies for all hypertension complicating pregnancies and suspected IUGR cases because it detects uteroplacental abnormalities. Earlier than biophysical profile and nonstress test.

\section{REFERENCES}

1. Aydin Tekey, Stuart Campbell, Doppler ultrasonography in obstetrics : Feter W Callen Text book of ultrasonography in Obst \& Gyanec 4th edition 2000

2. Divon MY: Umbilical artery Doppler velocimetry: Clinical Utility in high risk pregnancies. Am.J. Obstet, Gynaecol 174: 10: 1996.

3. Fong K, Ryan ML. Doppler velocimetry of fetal middle cerebral, renal arteries, interobserver study Jr. U/S Med. 1990 April 15 (4) : 317 -21

Katherine W Fong, Ame Ohlsson, To determine and compare the diagnostic performance of fetal MCA, renal, umbilical arterial Doppler for prediction of IUGR. performance of fetal MCA, renal, umbilical arterial Dop

5. Karsdorp VH, Van Vugt JM, Van Geijin HP, et al: Clinical significance of a b s e n t o reversed end diastolic velocity wave forms in umbilical artery. Lancet 344: 1664, 1994.

6. Wladimiroff JW, Tonge HM, Stewart PA: Dopplerultrasound assessment of c ere bral blood flow in human fetus. Br.J. Obstet, \& Gynaecol. 93:471:1986. 